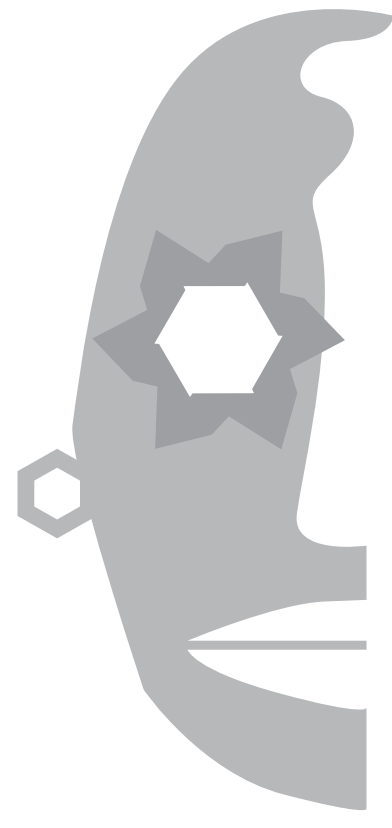

Werner

Mackenbach

Universidad de

Costa Rica

\title{
¿Black is black? El Caribe y Centroamérica más allá de África y la negritud
}

\section{Resumen}

En los estudios sobre el Caribe se ha vuelto un tópico común entender la región en términos de afrodescendencia y negritud. Con eso, se ha perfilado cierta tendencia de encerrar el espacio cultural tan diverso del Caribe y Centroamérica en una nueva concepción limitada y esencialista que hace abstracción de las múltiples y complejas convergencias transculturales a lo largo de su historia. Sin embargo, ya a partir de los años setenta y ochenta del siglo XX se han generado ensayos abarcadores e innovadores en y desde el espacio caribeño mismo que introducen nuevas dimensiones en los debates sobre caribeñidad, antillanidad, mestizaje, 'creolidad' etc. En las literaturas caribeñas y centroamericanas han emergido numerosas obras que tematizan, ironizan y parodian la búsqueda de una identidad exclusivamente negra de los Caribes y de los intentos de regresar a la "Madre África". El ensayo se dedica al análisis de este fenómeno en cuatro novelas de los Caribes francófono e hispanófono: Ti Jean l'horizon (1979) de Simone Schwarz-Bart (Guadalupe), Calypso (1996) de Tatiana Lobo (Costa Rica), Limón Blues (2002) de Anacristina Rossi (Costa Rica) y Black is black (2008) de Raphaël Confiant (Martinica).

Palabras clave: Caribe; Centroamérica; identidad; negritud; 'créolisation'; novela
Abstract
In scholarly resarch on the Caribbean it has become a common topic to understand the region in terms of afrodescendencia and négritude (blackness). With that a certain tendency to enclose the so diverse cul- tural space of the Caribbean and Central America in a new limited and essentialist conception has been taken place, by this prescinding from the multiple and complex processes of transcultural convergen- cy in the course of its history. However, as early as the seventies and 
eighthies of the XX century have been emerging comprehensive and innovative essays in and from the Caribbean itself that introduce new dimensions in the debates on caribbeaness, antillanité, mestizaje, creoleness, etc. In Caribbean and Central American literatures numerous oeuvres have been emerging that pick out as a central theme, ironize, and parody the search for an exclusively black identity of the Caribbeans and the efforts to return to "Mother Africa". This essay presents an analysis of this phenomena in four novels from the francophone and hispanophone Caribbeans: Ti Jean l'horizon (1979) by Simone Schwarz-Bart (Guadaloupe), Calypso (1996) by Tatiana Lobo (Costa Rica), Limón Blues (2002) by Anacristina Rossi (Costa Rica) and Black is black (2008) by Raphaël Confiant (Martinique).

Keywords: Caribbean; Central America; identity; blackness; creolization; novel.

\section{Introducción}

Back to Africa, Miss Matty?

Yuh noh know wha yuh dah-sey? Yuh haffe come from some weh fus Before yuh go back deh?

But de balance o' yuh family Yuh whole generation Oonoo all bawn dung a Bun grung Oonoo all is Jamaican! [...]

Louise Bennett, "Back to Africa"

En los estudios sobre el Caribe se ha vuelto un tópico común entender la región en términos de afrodescendencia y negritud. El descubrimiento y la recuperación del espacio caribeño en los estudios centroamericanos se ha desarrollado, incluso, casi exclusivamente en estos parámetros. Sergio Ramírez polemiza en su libro Tambor olvidado, publicado en 2007, en contra del discurso del mestizaje dominante durante siglos en los proyectos identitarios y de construcción de nación, que reducía el ser centroamericano a la "mezcla entre los conquistadores y colonizadores españoles y los pueblos aborígenes" (Ramírez, 2007: 9). Contra la "mutilación de nuestra historia para quitar de por medio el componente africano" (p. 10) insiste en este "componente cultural infaltable, chispa del genio total americano, lo negro" (p. 29).

No cabe duda que este reclamo de lo negro como constituyente de las culturas del Caribe y Centroamérica es más que justificado y ha generado un sinnúmero de estudios que recuperan ese legado. Sin embargo, con eso, se ha perfilado también una tendencia a encerrar el espacio cultural tan diverso del Caribe y Centroamérica en una nueva concepción limitada y esencialista que hace abstracción de las múltiples y complejas convergencias transculturales a lo largo de su historia. 
A partir de los años setenta y ochenta del siglo XX esta concepción comienza a ser cuestionada, con ensayos abarcadores e innovadores en y desde el espacio caribeño mismo que no solamente rompen con la tradición secular de construcciones identitarias basadas en múltiples exclusiones, sino que introducen nuevas dimensiones en los debates sobre caribeñidad, antillanidad, mestizaje, créolité etc. En las literaturas caribeñas y centroamericanas han emergido numerosas obras que tematizan, ironizan y parodian la búsqueda de una identidad exclusivamente negra de los Caribes y de los intentos de regresar a la "Madre África". A continuación, en este artículo se analizarán algunas novelas publicadas entre 1979 y 2008 en el Caribe insular y centroamericano.

\section{De la négritude a la créolité y la antillanité}

"On cessait d'être un étudiant essentiellement martiniquais, guadelupéen, guyanais, africain, malgache, pour n'être plus qu'un seul et même Étudiant noir. Terminée la vie en vase clos ...". Estas palabras, publicadas en 1934 en el No. 1 de la revista L'Étudiant noir fundada ese mismo año en París por Léon-Gontran Damas, Léopold Sédar Senghor, Birago Diop y Aimé Césaire, han sido entendidas comúnmente como la partida de nacimiento de un movimiento cultural con profundas repercusiones en, sobre y desde el mundo caribeño, con proyecciones más allá. Cinco años más tarde, este movimiento recibió las aguas bautismales en un poema-libro que se ha convertido en un clásico, no solamente de las literaturas caribeñas. En Cahier d'un retour au pays natal, publicado por primera vez en 1939 en la revista Volonté, el martiniqueño Aimé Césaire reclama que "es-hermoso-y-bueno-y-legítimo-ser-negro" (Césaire, 1993: 127). ${ }^{2}$ En la primera parte de este poema épico, el yo poético dibuja una imagen de la isla Martinica de miseria, inercia, hambre, resignación y desesperanza, y expresa su deseo de partir para encontrar su/una nueva identidad. En la segunda parte, el yo poético critica a la Europa colonialista y su tiranía sobre las Antillas y comienza a hablar de Martinica como "mi tierra". En la tercera parte (que cambia del tiempo pasado de las primeras dos partes al tiempo presente) su decisión es definitiva:

Acepto... acepto... completamente, sin reserva...

a mi raza que ninguna ablución de hisopo y de lirio

mezclados

podría purificar

$[\ldots]$

Acepto. Acepto

(Césaire, 1993: 105,107)

1 "Se deja de ser un estudiante esencialmente martiniqueño, guadalupeño, guyanés, africano, malgache, para ser no más que un Estudiante negro. Terminada la vida en un mundo cerrado..." (mi traducción, W.M.).

2 Cito aquí y en adelante de la edición bilingüe (francés-español) de 1993. 
Regresa a Martinica -Cuaderno de un retorno al país natal- para contribuir a superar el estado de miseria y opresión de su "raza" y desarrollar un movimiento que acabe con la resignación y la esclavitud, el movimiento de la négritude: ${ }^{3}$

mi negritud no es una piedra cuya sordera arremete contra el clamor del día mi negritud no es una mancha de agua muerta en el ojo muerto de la tierra mi negritud no es una torre ni una catedral se zambulle en la carne roja del suelo se zambulle en la carne ardiente del cielo agujerea el agobio opaco de su erguida paciencia (Césaire, 1993: 97)

Este elogio del negro/de lo negro como hermoso, bueno y legítimo, cantado inicialmente desde París donde se encuentran los intelectuales negros francófonos de las Antillas y África -entre ellos los mencionados Léon-Gontran Damas de Guayana Francés, Léopold Sédar Senghor y Birago Diop de Senegal- se convierte en un grito que tiene eco en diferentes regiones del mundo donde la presencia negra presenta una gran fuerza y se inscribe en un movimiento general de reclamo de los derechos, la dignidad y belleza de los negros/de lo negro, particularmente a partir de los años 20 y 30 del siglo XX. Son las décadas del florecimento de movimientos y tendencias artístico-culturales y reivindicatorios como el Harlem Renaissance en Estados Unidos, el Garveyismo en el Caribe y Centroamérica y el afrocubanismo, entre los que existen múltiples vasos comunicantes y que en toda su diversidad les une su proclamación de un âme noire, un alma negra como identidad infranacional de los negros en su totalidad, cuyas raíces se encuentran en la África precolonial, así como su afán de reencontrar esta identidad en el regreso, back to the roots, a los orígenes africanos y al continente africano (ver Gewecke, 2007: 194-195):

Ni Europeos, ni Africanos, ni Asiáticos: nosotros nos proclamamos Creoles" (Bernabé, Chamoiseau y Confiant, 2011: 11): estas palabras, enunciadas en un discurso durante el Festival Caraïbe en 1988 cerca de París por los intelectuales Jean Bernabé, Patrick Chamoiseau y Raphaël Confiant, también de Martinica, suenan como una respuesta directa al movimiento de la négritude y la búsqueda de las raíces africanas. El canto al negro/lo negro es sustituido por el elogio de la créolité. ${ }^{4}$

3 Este neologismo significa mucho más que tener una piel de color negro para lo que existe la palabra noirceur en francés (negrura); négritude reclama toda una cultura, historia y memoria.

4 El discurso fue publicado un año después (1989) en forma de libro bajo el título Éloge de la créolité, por la Universidad de Virginia en Estados Unidos; cito aquí de la traducción al español que se publicó por primera vez más de veinte años después en 2011 en Bogotá (ver Mackenbach, 2013, pp. 16-17). 
De hecho, sin negar la herencia de Césaire, los intelectuales martiniqueños responden a las críticas pronunciadas en contra del concepto de negritud en el contexto de los movimientos anticoloniales en África y de la izquierda en Europa Occidental, especialmente en Francia. Jean-Paul Sartre, por ejemplo, sostuvo en su ensayo "Orphée noir" (1948) que el concepto de negritud resultaba en un "racismo anti-racista" (Sartre, 1948: 14), un momento de negación y transición que tenía que ser superado por la creación de una sociedad sin razas (y sin clases), crítica que fue compartida por Frantz Fanon en su libro Peau noir, masques blancs (1952) (ver Gewecke, 2007: 196-197). Bernabé, Chamoiseau y Confiant resaltan que:

Originalmente llena del deseo de darnos domicilio en el aquí de nuestro ser, durante las primeras olas de su despliegue, la Negritud estuvo marcada por un modo de la exterioridad: exterioridad de las aspiraciones (el África madre, el África mítica, el África imposible), exterioridad de la expresión de la relación (el Negro con mayúscula, todos los oprimidos de la tierra), exterioridad de la afirmación de sí (somos africanos). Inevitable momento dialéctico. Trayecto indispensable. Terrible desafío el de poder salir de ahí para por fin construir una nueva síntesis, provisional ella misma, en el recorrido abierto de la Historia, de nuestra historia (Bernabé, Chamoiseau y Confiant, 2011, p. 17).

Este discurso-ensayo fundacional de finales de los años ochenta abre nuevos horizontes y movimientos/tendencias en el afán de "[c]omprender lo que es lo antillano" (Bernabé, Chamoiseau y Confiant, 2011: 19) que emergen a partir de ese momento, no solamente en el Caribe francófono (Bernabé, Chamoiseau, Confiant, Édouard Glissant, Maryse Condé) sino también el hispanófono (Antonio Benítez Rojo) y el anglófono (Edward Kamau Brathwaite, Derek Walcott) y que piensan los Caribes en términos de créolité, antillanité, créolisatión, chaos-mon$d e$, fractalidad e identidad relacional. ${ }^{5}$

\section{El fin del sueño africano}

Paralelamente $-\mathrm{y}$ de hecho con cierta anticipación- en las literaturas caribeñas y centroamericanas se abre un proceso de cuestionamiento de algunas premisas fundamentales de un concepto encerrado y estático de negritud y del regreso a las raíces africanas, un proceso que también se desarrolla simultáneamente en los Caribes francófono, hispanófono y anglófono. Ejemplos significativos de este proceso son las cuatro novelas a las que nos referimos a continuación: Ti Jean l'horizon (1979), de Simone Schwarz-Bart (Guadalupe); Calypso (1996), de Tatiana Lobo (Costa Rica); Limón Blues (2002), de Anacristina Rossi (Costa Rica), y Black is black (2008), de Raphaël Confiant (Martinica).

5 Ver acerca de algunas de estas conceptualizaciones: Mackenbach, 2013. 
En su novela Ti Jean l'horizon, publicada a finales de los años setenta en Francia, la escritora guadalupeña Simone Schwarz-Bart ${ }^{6}$ relata la vida de los habitantes del pueblo Fond-Zombi en la isla de Guadalupe, quienes viven en la miseria, la pobreza y el sufrimiento, en dependencia de los propietarios blancos de las plantaciones de azúcar. El pueblo está dividido en los de arriba (los descendientes de esclavos cimarrones que conservan el legado africano) y los de abajo (que se han conformado con la civilización blanca). Las chozas de los de arriba son abandonadas sucesivamente y parece que no hay alternativa a la subordinación a los colonos blancos. Con la aparición de un monstruo mítico (la Bête) que devora el sol, fuente de la vida -símbolo de la conciencia perdida de una cultura propia, negra- que somete a los de abajo a una nueva esclavitud, el destino de los habitantes de Fond-Zombi parece tomar otro rumbo. El abuelo Wadembo destina a Ti Jean a recuperar la identidad de Guadalupe. Ti Jean se deja tragar por la bestia y llega pasando por lejanos mundos siderales a otro mundo para encontrarse siglos atrás en África, en la región natal de Wadembo a orillas del río Níger en los tiempos de la caza de esclavos. Ti Jean se siente parte del paisaje africano y la realidad africana le parece muy similar a la vida en Guadalupe. Sin embargo, no deja de sentirse como extranjero, fóraneo; el mundo africano con sus usos y costumbres le resulta inaccesible, como algo superficial, sin poder penetrar a fondo esta cultura. No encuentra el África que quiere llevar a Guadalupe, su viaje no es un retour aux sources, un regreso a las raíces.

A la pregunta de un viejo al que encuentra en la curva del Níger, sobre qué buscaba entre ellos, Ti Jean le contesta que su abuelo Wademba lo mandó para encontrar a los suyos en el pueblo de Obanishé y que sería recibido como un hermano. La respuesta del viejo es tajantemente negativa:

-Eh bien je m'en réjouis pour toi, car tu sais maintenant ce qui te reste à faire... Les oiseaux vont avec les oiseaux, c'est bien connu, et les animaux à poil avec leurs semblables... [...] retourne parmi les tiens... - Les miens, ne suis-je parmi eux ?

- Parmi les tiens ? Non, tu es pour nous comme ces animaux que l'on voit parfois dans la brousse, et pour lesquels on ne dispose pas de nom, voilà tout : et ton langage est pour nous comme la nuit, tes paroles sont pour nous comme la nuit, tes paroles sont pour nous comme des cris de chouette dans la nuit... [...] va-t'en, retourne parmi les tiens... (Schwarz-Bart, 2004: 164-165).

A través de un viaje por el reino de los muertos, Ti Jean regresa a la isla sin haber encontrado la identidad guadalupeña en África. Este regreso no es -como se lo había

6 Simone Schwarz-Bart (Brumant), hija de padres guadalupeños, nació en 1938 en Francia y regresó con ellos a Guadalupe a la edad de tres años. Realizó estudios en Guadalupe, Francia y Senegal. Es autora de novelas, relatos, obras de teatro y ensayos (entre estos Hommage à la femme noire, junto con André Schwarz-Bart, en siete volúmenes, 1989). 
planteado antes de iniciar el viaje- un fin, sino un nuevo comienzo, como comenta el narrador al final de la novela en el "Livre Neuvième. La fin et le commencement":

[...] il voyait maintenant, nostr'homme, que cette fin ne serait qu'un commencement ; le commencement d'une chose qui l'attendait là, parmi ces goupes de cases éboulées, ces huttes, ces abris de fortune sous lesquels on se racontait à voix basse et l'on rêvait de torches simplement plantées dans la terre... (Schwarz-Bart, 2004: 314).

En Calypso, novela publicada en 1996,Tatiana Lobo 7 retoma el motivo de Ti Jean ( $\sin$ hacer referencia a este nombre) y del viaje a África en búsqueda de la identidad afro-caribeña. ${ }^{8} \mathrm{Al}$ igual que Simone Schwarz-Bart, recurre a elementos mágico-realistas y oníricos en su relato de los destinos de un pueblo en la costa del Caribe costarricense (Parima Bay), a través de la historia de tres generaciones de mujeres (Amanda, Eudora, Matilda; al mismo tiempo, los subtítulos de las tres partes de la novela). El pueblo recibe su nombre de los habitantes en alusión al primer blanco que vino a la costa, Lorenzo Parima. Lo acompaña un excompañero de trabajo, el negro Alphaeus Robinson, hijo de un migrante de St. Kitts, isla de las Antillas Menores, y de una joven oriunda de la isla de San Andrés. A él le llaman "Plantintáh", por su "desmesurada afición por ciertas golosinas de masa rellenas con plátano dulce teñido de rojo vegetal, que en buen inglés se escribía plaintain tart, pero que hablado en la forma dialectal de la región sonaba aproximadamente así, plantintáh" (Lobo, 1996: 13) y también "Jicaritas de Agua Dulce", por la predilección que tienen las prostituas blancas de su burdel preferido por el portador de ese "apodo expresivo y cariñoso con el que lo distinguían de la clientela ordinaria" (p. 13). ${ }^{9}$

La novela es un elogio de las culturas del Caribe y una denuncia de las fuerzas destructoras del progreso de la "civilización" blanca, como sostuvo la autora en una entrevista: "Sí, es un homenaje. Sobre todo, quise dejar testimonio de cómo la cultura dominante está destruyendo la cultura de los pueblos del Caribe costarricense" (Brenes Molina, 2002: 8). Plantintáh -muy similar a Ti Jean en la novela de Simone Schwarz-Bart- ya muerto realiza un viaje espectral a África para buscar sus raíces y las de la cultura afro-caribeña de Costa Rica. Pero, al igual que Ti Jean, regresa al Caribe centroamericano sin haberlas encontrado.

7 Tatiana Lobo Wiehoff nació en 1939 en Chile en una familia de descendencia alemana y vive en Costa Rica desde 1967. Realizó estudios en Chile, España y Costa Rica. Ha publicado novelas, relatos, obras de teatro y ensayos (entre estos Blancos y negros, todo mezclado, junto con Mauricio Meléndez, 1997).

8 También en la obra teatral Ti-Jean and his Brothers (1970), el escritor Derek Walcott (St. Lucia *1930) recurre a la figura de Ti Jean. La obra versa sobre las luchas por las identidades afro-caribeñas en confrontación con los efectos de colonización. Ignoro si los elementos intertextuales de la novela Calypso se deben a un conocimiento de la novela de Simone Schwarz-Bart y la obra teatral de Derek Walcott por parte de Tatiana Lobo.

9 Ver Mackenbach, 2003. 
Sufre "un gran desgaste viajando por Africa, donde sufre muchas desilusiones y pasa grandes dificultades, sin encontrar la forma de renacer" (Lobo, 1996: 184). El balance de este viaje (pronunciado en palabras de su hermana Emily) es muy claro: [...] los africanos habían perdido el contacto con las energías primarias del planeta, sufrían demasiadas penurias, y las enfermedades, las guerras y el hambre los arrancaban de sus tribus y de sus casas para vagar, como almas en pena, por la inmensidad del continente (Lobo, 1996: 184-185). Como en la novela de Schwarz-Bart, las raíces africanas están cortadas para siempre, África no es más que "una pesadilla", "una grande y profunda desesperanza" (Lobo, 1996: 185). ${ }^{10}$

En la novela Limón Blues, publicada en 2002, Anacristina Rossi ${ }^{11}$ no se vale de elementos del realismo mágico, sino de un realismo documental ficcionalizado en clave de novela histórica para relatar la historia de unos personajes en Puerto Límón, en la costa del Caribe costarricense en las primeras cuatro décadas del siglo XX. A base de un estudio minucioso en archivos (en el que rescató principalmente los periódicos escritos en inglés, entre otros documentos), la autora crea una imagen de la convivencia multiétnica y transnacional en Puerto Limón en esa época, y muy en especial de la presencia y las repercusiones del movimiento negro liderado por el jamaicano Marcus Garvey y el líder local, Samuel Nation, con su proyecto de "repatriar" a millones de negros de todo el mundo a África.

No obstante esta (re)construcción empática de las luchas de los negros por su emancipación en el Caribe costarricense, la novela llega a conclusiones muy parecidas a las dos novelas mencionadas anteriormente, en relación con la negritud y la búsqueda de la raíces africanas. Cuando el primer barco de la Black Star Line, creada por la U.N.I.A. (Universal Negro Improvement Association) de Marcus Garvey llega a las costas de África lleno de negros, el proyecto fracasa definitivamente:

Cuando se vislumbró la costa de Liberia, la misión se reunió a repasar instrucciones. Ya el cargamento con material comprado por la U.N.I.A. -con un valor de cincuenta mil dólares- y enviado meses atrás debía estarlos esperando. Suficiente para empezar a construir.

$\mathrm{Al}$ acercarse el barco a tierra, la tripulación del vapor se puso agresiva y malcriada con los garveítas. Orlandus no podía comprender lo que estaba pasando.

Dos oficiales fueron a buscarlo a su camarote y lo detuvieron. El miraba fascinado la costa africana.

10 Ver Mackenbach, 2011, p. 189.

11 Anacristina Rossi nació en 1952 en Costa Rica y vivió algunos años de su infancia en la región del Caribe de ese país. Realizó estudios en Costa Rica, Inglaterra, Francia y Holanda. Ha publicado novelas, cuentos y ensayos (entre estos "El corazón del desarraigo: la primera literatura escrita afrocostarricense", 2009). 
Lo llevaron a un sitio en la segunda cubierta donde estaban detenidos los otros miembros de la misión. El capitán les leyó un mensaje que acababa de recibir. Decía:

"El Gobierno de la República de Liberia advierte a todas las compañías de vapores que a ningún miembro del movimiento llamado 'de Garvey' se le permitirá desembarcar y que cualquier compañía que intente evadir esta disposición se verá obligada a transportar a los garveítas a los Estados Unidos (Rossi, 2002: $311)$.

Orlandus Robinson, uno de los protagonistas de la novela (un personaje inventado entre personajes ficcionalizados que hacen referencia a personas reales como Sam Nation y Marcus Garvey), inmigrante jamaicano y exmilitante de la U.N.I.A., resume su experiencia en el movimiento de Garvey:

We Negroes had this dream: regresar al África. Al principio era un sueño. Después se convirtió en una friggin necesidad. Y cuando más lo necesitábamos el regreso falló y ahora no tenemos nada. En Jamaica no hay futuro. En las otras islas menos. En Cuba el futuro se nos acabó. Aquí en Limón también todo se termina [...] El orgullo de raza que Garvey fomenta es superficial. Look out fe me, los negros nos desconocemos [...] (Rossi, 2002: 346-347).

En una plática con Sam Nation, Orlandus es categórico: “[...] ahora que lo de África fracasó, no tenemos futuro" (Rossi, 2002: 345). Y el hijo de Orlandus e Irene, Denmark, se burla después de la muerte de su padre en una conversación con su madre: “"África, el país donde todos tendremos dignidad, how ridiculous, y peor ridículo el fracaso de las estúpidas empresas de Garvey"' (Rossi, 2002: 380). ${ }^{12}$

Finalmente, en la novela Black is black, publicada en 2008, Raphaël Confiant ${ }^{13}$ va aún más allá en la deconstrucción de lo africano/lo negro como base de una identidad caribeña. La novela relata la historia de Abel, un novelista de Martinica que está escribiendo una novela llamada Parcours d'un corps que oscila entre lo romántico, lo erótico y lo pornográfico. En capítulos sucesivos la novela alterna entre los dos relatos: la historia de Abel (novela) y la novela escrita pero nunca terminada por Abel (novela en la novela). En el primer relato, el protagonista sucumbe a las tentaciones de un profeta de la regeneración de la raza negra que les promete a sus fieles que serán repatriados a la madre tierra africana gracias a la evocación de los dioses del Egipto antiguo. En el segundo relato, el narrador

12 También la novela Une saison à Rihata (1981) de Maryse Condé (Guadalupe) tematiza el rechazo de los caribeños por los africanos en la historia de una fallida integración de una mujer antillana junto con su esposo africano en su pueblo natal. Ver Mackenbach, 2011: 189.

13 Raphaël Confiant nació en 1951 en Martinica y ha vivido una gran parte de su vida en Francia. Realizó estudios en Martinica y Francia. Ha publicado numerosas novelas, cuentos (en créole y francés) y ensayos (entre estos Éloge de la créolité, junto con Jean Bernabé y Patrick Chamoiseau, 1989, Lettres créoles: tracées antillaises et continentales de la littérature [1635-1975], junto con Patrick Chamoiseau, 1991, y Aimé Césaire, une traversée paradoxale du siècle, 1993). 
de la novela en la novela cuenta su relación erótico-sexual con la mujer adorada, l'Innomée (ou l'Irrésolue). Recurriendo a técnicas carnavalescas, paródicas e irónicas, en esta novela el proyecto de volver a África y encontrar la identidad negra ha perdido todo carácter serio. Es la obsesión de un profeta medio loco que fracasa antes de poder ponerla en práctica, una quimera que nunca se materializará. En la narración a nivel uno se lee:

J'avais à peine entamé la remontée de l'avenue Jean-Jaurès qu'un adepte du " peuple du Cham ", hirsute et vêtu d'un boubou multicolore, m'alpagua et se mit à déballer son jargon messianique :

"Repentez-vous, monsieur Abel ! Vous vous êtes fourvoyé dans le monde des Diables Blancs depuis trop longtemps mais leur règne est sur le point de s'achever. Nos ancêtres, constructeurs des pyramides d'Égypte et du Sphinx, rédacteurs de la Bible et du Coran, bâtisseurs de la richesse des Amériques, nous ordonnent de prendre leur relève. Bientôt, nous reconstruirons un monde entièrement noir et..."

Depuis quelques mois, en effet, un grand prophète rescapé de Barbès ou de Belleville, se prétendant authentique Africain, Eskrou Bilongo (de son vrai nom Francis Édouard-Jacques comme tout un chacun par ici), prosélytait dans le quartier expliquant que Moïse était noir, Jésus était noir, Shakespeare idem. Alors, pourquoi, vous les Nègres martiniquais, vous refusez votre noircitude, hein ? Bande d'aliénés, d'assimilés au monde blanc! Lachez le veau d'or européen pour la vache sacrée chamitique ! Évidemment, le prophète pouvait pas me voir en peinture vu que j'avais trop de respect pour l'Afrique et sa culture pour me croire africain. À moins, que ladite culture ne s'apprenne aussi facilement que la table de multiplication et le swahili plus vite que le petit-nègre ! Bref, j'étais un hérétique, un danger public, une crapule, un cartésien attardé, un vodkaïnomane doublé d'un érotomane, un fils de pute et un écrivassier de merde [...] Pour l'heure, aucune des stratégies géniales mises au point par Eskrou Bilongo pour parvenir à ses fins n'avait trouvé l'issue escomptée : je me baladais toujours goguenard à travers les rues mal famées de l'En-Ville, insensible à la grandiose destinée du peuple de Cham (Confiant, 2008: 20-21).

Título íronico -black is (not) black-, la identidad negra no existe, lo negro se caracteriza por su diversidad, multiplicidad y contemporaneiad. En la novela en la novela (nivel dos de la narración) el escritor-personaje canta el elogio del cuerpo de su amada:

Je découvrais une jeune femme intelligente et jolie, mais sans plus. Notre petit monde insulaire regorge de beautés plus fatales: mulâtresses ravageuses dont la soie du regard vous cloue sur place, chabines piquantes et dorées avec qui on frétille d'envie de danser le quadrille, Négresses noires et magnifiques comme un minuit d'hivernage, câpresses dont les poètes régionalistes on trop vanté la peau couleur de sapotille mais qui sont, vrai de vrai, d'authentiques 
ensorceleuses, indiennes-coulies si tendres et douces qu'on jurerait des murmures faites chair ou encore ces bâtards-chinoises ou bâtards-syriennes dont le port de tête ou le tour de reins relève de l'enchantement (Confiant, 2008: 33).

La descripción de la amada se convierte en una alegoría de la diversidad caribeña. Lo negro caribeño es fragmentado, existe solamente en plural y de forma múltipe y contradictoria.

\section{Más allá de la caribeñidad y la créolité}

La novela de Raphaël Confiant se hace eco de las tendencias más recientes en el pensamiento caribeño que, a partir de una crítica de la créolité -concepto que tiende a encerrar la diversidad, multiplicidad y lo contradictorio de las culturas caribeñas en una nueva identidad fija, arraigado ya no en lo negro sino en lo caribeño-créole - han desarrollado nuevos conceptos que permiten pensar las diversidades caribeñas más allá de una identidad única y estable, proponiendo conceptos como créolisation, identité-relation, tout-monde y chaos-monde, entre otros, especialmente presentes en la obra de otro escritor-intelectual martiniqueño, Édouard Glissant. ${ }^{14}$

En la novelística, estas tendencias de un pensamiento nomádico y archipiélico han tenido amplias repercusiones. Un ejemplo destacado entre muchos otros textos es la novela Les belles ténébreuses de Maryse Condé ${ }^{15}$, publicada en 2008, que puede ser leída como una puesta en ficción novelesca de la tesis de Édouard Glissant de la créolisatión como proceso que no se limita a los Caribes, sino que toma forma en las culturas del tout-monde, en todo el mundo. La novela narra la vida nomádica de Kassem, hijo de un padre de Guadalupe y una madre de Rumania, no solamente entre diferentes países y culturas de África, Europa y Norteamérica, sino también en identidades cambiantes. La novela Dans la maison $d u$ père de Yanick Lahens ${ }^{16}$, publicada en 2000, narra el doble exilio de la haitiana Alice entre Nueva York y Haití y la imposibilidad de establecer identidades fijas en ambos mundos. El regreso a su isla es equivalente a otro exilio, después de haber vivido por años en Nueva York: "Une fois de plus, le temps se joue de moi et me retourne comme une paille dans la main du vent" (154). Llama la atención que paralelamente a los cambios de conceptos en los ensayos del y sobre el Caribe

14 Ver al respecto Mackenbach, 2013: 22-27.

15 Maryse Condé nació en 1937 en Guadalupe. Realizó estudios en Guadalupe y Francia, vivió y trabajó en Guinea, Ghana, Senegal, Francia y Estados Unidos. Ha publicado novelas, cuentos, literatura infantil, obras teatrales y ensayos (entre estos "Pourquoi la Négritude? Négritude ou Révolution", 1973, "Créolité without Creole Language", 1998, "The Stealers of Fire: The French-Speaking Writers of the Caribbean and Their Strategies of Liberation", 2004).

16 Yanick Lahens nació en 1951 en Haití. Realizó estudios en Francia y regreso a Haití para trabajar como profesora universitaria. Ha publicado novelas, cuentos y ensayos (entre estos L'Exil: entre l'ancrage et la fuite, l'écrivain haïtien, 1990). 
mencionados arriba se perfilan cambios en la metafórica de las producciones novelísticas caribeñas: "Las metáforas de la raíz [también su forma cortada] y del rizoma se transforman en la de la pajita" (Mackenbach, 2013: 191).

Estas tendencias en las literaturas caribeñas -especialmente la ensayística y la novelística- sugieren algunas conclusiones para el estudio y el entendimiento de los procesos (trans) culturales caribeños:

1) No es posible hablar de y estudiar el Caribe en singular, sino solamente en sus diversidades, de los Caribes en plural.

2) Las literaturas caribeñas y centroamericanas se relacionan e intersecan a manera de vasos comunicantes (lo hemos visto en la presencia del motivo de Ti Jean en obras de los Caribes francófono, hispanófono y anglófono), de ahí la necesidad de estudios comparados y transnacionales.

3) En la literatura (entendida como obras de ficción y creación) se manifiestan con anticipación tendencias culturales antes de que se vuelvan visibles y dominantes en otros campos de producción intelectual (lo hemos visto en relación con el discurso sobre créolité/créolisation).

4) La literatura es un inmenso e inagotable archivo de experiencias de vida y convivencia que hay que estudiar en toda su complejidad y multiplicidad, de ahí la necesidad de estudios inter- y transdisciplinarios. ${ }^{17}$

5) Es preciso realizar una relectura del concepto de négritude en toda su historicidad, multiplicidad y sus diversas facetas, más allá de su canonización y dogmatización.

¿Black is black? No. No hay una negritud, sino negritudes. Black is not black es mucho más que sólo negro. Cabe recordar que en la obra de Aimé Césaire ya se podían ver estas tendencias: el regreso es un retorno, no a África sino a Martinica, a las Antillas ${ }^{18}$. En su Discurso sobre el colonialimo, publicado once años después de Cahier d'un retour au pays natal, la lucha por los derechos y la dignidad de los negros se convierte en la lucha contra la opresión colonial en general. ${ }^{19} \mathrm{Como}$

17 Es uno de los propósitos del programa de investigación "CrossWorlds - World(s) Crossing. Convergencias transculturales en Centroamérica y el Caribe" y de la "Red de estudios transareales de Centroamérica y el Caribe", con sede en la Universidad de Costa Rica, en los que participan estudiosos de varias universidades y múltiples disciplinas de Costa Rica, Centroamérica, América Latina, Europa y Norteamérica.

18 Ver en contra de una comprensión ahistórica de la negritud el ensayo de Oliva, 2011, y acerca de una “definición de la negritud amplia, flexible” el trabajo de López Muñoz, 2011: 95. Oliva sostiene: “ [...] Césaire destaca la dimensión histórica de la negritud que muchas veces se pierde en la abstracción del concepto, aunque él la ha hecho manifiesta desde el Cuaderno de un retorno al país natal. Para el martiniqueño, la negritud no sólo implica la valorización de la cultura africana sino también entender que existe un quiebre con ese mundo dado por la diáspora forzada y la esclavitud. No se trata, por lo tanto, tan sólo de recuperar una cultura de origen, sino que también de apropiarse de una memoria traumática, de valorizar la cultura creada a partir de la diáspora y de reconocerse como parte del proceso histórico caribeño" (Oliva, 2011: 23).

19 Ver el artículo de Marambio de la Fuente, 2011. 
señala la poeta jamaicana Louise Bennett en la última estrofa de su poema "Back to Africa" ${ }^{20}$ citado en el epígrafe de este ensayo, el lugar de esta lucha es el Caribe, son los Caribes:

Go a foreign, seek yuh fortune.

But noh tell nobody say

Yuh dah-go fe seek yuh homeland.

For a right deh so yuh deh!

(Bennett, 1966: 215) $)^{21}$

\section{Referencias}

Bennett, Louise (1966). "Back to Africa". En Jamaica Labrish. Kingston: Sangster's Book Stores, 214-215.

Bernabé, Jean, Patrick Chamoiseau y Raphaël Confiant (2011). Elogio de la Creolidad. Trad. Mónica María del Valle Idárraga y Gertrude Martin-Laprade. Bogotá: Editorial Pontificia Universidad Javeriana (primera edición en francés 1989).

Brenes Molina, José Jacinto (2002). "Entrevista a Tatiana Lobo: literatura y sociedad". Comunicación, 23.12, 7-10.

Césaire, Aimé (1983). Cahier d'un retour au pays natal. Paris: Présence Africaine (primera edición en francés 1939).

Césaire, Aimé (2006). Discurso sobre el colonialismo. Trad. Mara Viveros Vigota. Madrid: Editorial Akal (primera edición en francés 1950).

Césaire, Aimé (1993). Cuaderno de un retorno al país natal. Madrid: La Casa del Libro (edición bilingüe francés-español).

Condé, Maryse (1981). Une saison a Rihata. París: Éditions Robert Laffond.

Confiant, Raphaël (2008). Black is black. Monaco: Éditions Alphée, Jean-Paul Bertrand.

Fanon, Frantz (1952). Peau noir, masques blancs. París: Seuil.

20 Louise Simone Bennett-Coverley nació en 1919 en Kingston, Jamaica, y murió en 2006 en Scarborough, Ontario. Estudió folclore jamaicano y fue docente de dramaturgia. Vivió en Jamaica, Gran Bretaña y Canadá. Entre sus publicaciones más importantes se encuentran los libros de poemas y relatos Jamaica Labrish (1966) y Anancy and Miss Lou (1979), así como su interpretación de la canción tradicional "Day Dah Light" (1954) grabada por Harry Belafonte como "Day-O" o "Banana Boat Song".

21 En la traducción del creole al inglés esta estrofa dice: "Travel, seek your fortune, / but tell no one here / that you are going to seek your homeland, / because you are already there." Ver el poema completo y su traducción al inglés en: $<$ http://idurae.blogspot.com/2005/10/back-to-africa-original-louise-bennett.html $>$. 
Gewecke, Frauke (2007). Die Karibik. Zur Geschichte, Politik und Kultur einer Region. Frankfurt am Main. Vervuert Verlag.

Lahens, Yanick (2000). Dans la maison du père. Monaco: Le Serpent à Plumes.

Lobo, Tatiana (1996). Calypso. San José: Ediciones FARBEN.

López Muñoz, Ricardo (2011). “Tensiones y continuidades en la historicidad de la negritud: Aimé Césaire ante Frantz Fanon”. En Elena Oliva, Lucía Stecher y Claudia Zapata (eds.). Aimé Césaire desde América Latina. Diálogos con el poeta de la negritud. Santiago de Chile: Centro de Estudios Culturales Latinoamericanos, Universidad de Chile, 79-96.

Mackenbach, Werner (2003). "Representaciones del Caribe en la narrativa centroamericana contemporánea". Istmo. Revista virtual de estudios literarios y culturales centroamericanos 5 (2003). Recuperado en <http://istmo.denison.edu/n05/articulos/representaciones.html>.

Mackenbach, Werner (2011). “¿De la identidad a la sociabilidad? Representaciones de la convivencia en las literaturas centroamericanas y caribeñas". En Ottmar Ette, Werner Mackenbach, Gesine Müller y Alexandra Ortiz Wallner (eds.). Trans(it)Areas. Convivencias en Centroamérica y el Caribe. Un simposio transareal. Potsdamer inter- und transkulturelle Texte (POINTE), Band 1. Berlín: edition tranvía, Verlag Walter Frey, 176-198.

Mackenbach, Werner (2013). "Del éloge de la créolité a la teoría del caos. Discursos poscoloniales del Caribe más allá de la identidad". Cuadernos Inter $\cdot c \cdot a \cdot m b i o, 10.11,15-29$.

Marambio de la Fuente, Matías (2011). "Pensamiento histórico en Discurso sobre el colonialismo: la historicidad como condición de posibilidad de una crítica anticolonial". En Elena Oliva, Lucía Stecher y Claudia Zapata (eds.). Aimé Césaire desde América Latina. Diálogos con el poeta de la negritud. Santiago de Chile: Centro de Estudios Culturales Latinoamericanos, Universidad de Chile, 41-56.

Oliva, Elena (2011). "La figura de Aimé Césaire. Trayectoria y pensamiento anticolonial en el poeta de la negritud". En Elena Oliva, Lucía Stecher y Claudia Zapata (eds.). Aimé Césaire desde América Latina. Diálogos con el poeta de la negritud. Santiago de Chile: Centro de Estudios Culturales Latinoamericanos, Universidad de Chile, 15-25.

Ramírez, Sergio (2007). Tambor olvidado. San José: Aguilar.

Rossi, Anacristina (2002). Limón Blues. San José: Alfaguara. 
¿Black is black? El Caribe y Centroamérica más allá de África y la negritud

Sartre, Jean-Paul (1948). “Orphée noir”. En Anthologie de la nouvelle poésie nègre et malgache. Léopold Sédar Senghor. París: Presses Universitaires de France, IX-XLIV.

Schwarz-Bart, Simone (2004). Ti Jean l'horizon. París: Seuil (primera edición 1979). 